\title{
BCG-induced Susceptibility of Mice to Challenge with Pseudomonas aeruginosa
}

\author{
By SHAM LAL, ${ }^{1 *}$ MASAO MITSUYAMA, ${ }^{1}$ NUBUO OGATA, ${ }^{1}$ \\ MASAKAZU MIYATA, ${ }^{1}$ SHUNJI MIAKE ${ }^{1}$ AND KIKUO NOMOTO ${ }^{2}$ \\ Department of Microbiology ${ }^{1}$ and Division of Immunology in Cancer Research Institute ${ }^{2}$, School \\ of Medicine, Kyushu University, Fukuoka 812, Japan
}

(Received 9 March 1982; revised 7 July 1982)

\begin{abstract}
Mice infected with Mycobacterium bovis, BCG, were shown to be highly susceptible to subsequent challenge with Pseudomonas aeruginosa. The susceptibility was characterized by the enhanced mortality and shortened survival after challenge with $P$. aeruginosa. BCG-treated mice did not show any enhanced susceptibility to challenge with Gram-positive bacteria such as Staphylococcus aureus or Listeria monocytogenes. BCG-treated mice eliminated $P$. aeruginosa from their organs in a pattern similar to that in untreated mice. There was no significant difference in the bactericidal activities of polymorphonuclear cells and macrophages between BCG-treated and untreated mice. An equal amount of endotoxin was detected by the Limulus lysate assay in the blood of both BCG-treated and untreated mice after challenge with $P$. aeruginosa. The enhanced susceptibility induced by BCG pretreatment could be decreased when the mice were rendered LPS-tolerant by injections of small amounts of LPS. These results suggest that BCG-induced susceptibility to $P$. aeruginosa can be ascribed to an enhanced susceptibility to the lethal effect of LPS produced by challenge bacteria, and not to the impairment of the ability to eliminate infected bacteria.
\end{abstract}

\section{INTRODUCTION}

Pseudomonas aeruginosa is one of the most important causes of nosocomial infections (Benett 1974; Reinarz et al., 1979) and lethal infections in burned and other compromised hosts (Peavy et al., 1979; Reynolds et al., 1975). In addition to chemotherapy with antibiotics, two approaches have been used to control pseudomonas infection. One major approach was immunization with vaccine obtained from $P$. aeruginosa, and satisfactory results were obtained in some animal models (Pier et al., 1978; Liebermann et al., 1980). Another approach may be to find agents capable of augmenting non-specific resistance against $\boldsymbol{P}$. aeruginosa, since Corynebacterium parvum (Miyata et al., 1980), Mycobacterium bovis strain BCG (Matsuo et al., 1977) or muramyl dipeptide (Chedid \& Parant, 1971; Matsumoto et al., 1981) have been reported to increase non-specific resistance against several kinds of bacterial infections. Treatment with complete Freund's adjuvant or BCG restores the resistance against $\boldsymbol{P}$. aeruginosa in granulocytopenic mice (Buhles \& Shiferine, 1977). The resistance of normal mice against primary infection with $P$. aeruginosa seems to be attributable mainly to polymorphonuclear cells (PMN) but not to macrophages (Tatsukawa et al., 1979). On the other hand, complete Freund's adjuvant and BCG have been shown to activate mainly the functions of macrophages. In the present study, which was carried out to determine the effect of BCG treatment in normal mice, it was found that BCG treatment did not augment the resistance but rather enhanced a lethal effect of pseudomonas infection. In addition such BCG treatment augmented the resistance against Listeria monocytogenes to which resistance had been reported to depend mainly upon the function of macrophages (Tatsukawa et al., 1979). 


\section{METHODS}

Mice. An outbred strain of ddy mice was purchased from Kyodo Experimental Animal Co., Kumamoto, Japan. Athymic nude mice and their euthymic littermates $(\mathrm{nu} /+)$ of BALB/C background were obtained from Shizuoka Cooperative for Experimental Animals, Shizuoka, Japan. They were used at 7 to 8 weeks of age.

Micro-organisms. A French strain of BCG from the Pasteur Institute, Paris, was used for pretreatment of mice which were challenged with Pseudomonas aeruginosa (strain KC-2) maintained in our laboratory. In one experiment mice were challenged with Staphylococcus aureus (strain 18z) or Listeria monocytogenes (EGD).

$B C G$ pretreatment and challenge infection. BCG organisms were collected from 10-14 d slant cultures on Ogawa's medium (containing: $\mathrm{KH}_{2} \mathrm{PO}_{4}, 1.0 \mathrm{~g}$; sodium glutamate, $1.0 \mathrm{~g}$; glycerol, $6 \mathrm{ml}$; distilled water, $100 \mathrm{ml}$; homogenized whole eggs, $200 \mathrm{ml}$, and $2 \%(\mathrm{w} / \mathrm{v})$ aqueous malachite green solution, $6 \mathrm{ml}$ ) (Takeya et al., 1977), gently homogenized with glass beads in phosphate-buffered saline. Mice were injected intravenously (i.v.) with a suspension containing $1.0 \mathrm{mg}$ BCG $\left(1-2 \times 10^{6} \mathrm{c}\right.$.f.u.). Mice treated with BCG or control untreated animals were challenged thereafter. After two serial passages in mice, bacteria used for challenge were cultured in Tryptone Soy broth (Difco) for 10-12 h and resuspended in phosphate-buffered saline. The bacterial suspensions were kept at $-70^{\circ} \mathrm{C}$ and used immediately after thawing. The stock suspension was diluted for the challenge injection. The number of bacteria in the challenge dose, enumerated by pour-plate method, was $1.8 \times 10^{6}$.

Assessment of mortality of mice and growth of bacteria after the challenge infection. Groups of mice (5-10 mice per group) were treated with BCG 7 to $21 \mathrm{~d}$ before i.v., intramuscular (i.m.) or intraperitoneal (i.p.) challenge with $1.8-3.0 \times 10^{6}$ c.f.u. of $P$. aeruginosa. Death was recorded up to $7 \mathrm{~d}$ after the challenge. Mean survival time of mice that died was calculated by dividing the total days of survival by the number of dead mice. Growth of $P$. aeruginosa in vivo was measured after challenge by removing injected thigh muscle 5,24 or $48 \mathrm{~h}$ after inoculation. The muscle was homogenized in a Teflon homogenizer, and the homogenate was serially diluted 10-fold with phosphatebuffered saline. Each sample $(0.1 \mathrm{ml})$ was spread on nutrient agar, and the bacterial count per muscle was estimated from the colony count after incubation at $37^{\circ} \mathrm{C}$ for $20 \mathrm{~h}$. Also spleen, kidney, liver and blood were removed from infected mice $10 \mathrm{~h}$ after i.v. inoculation of bacteria. The number of bacteria contained in one organ or $1 \mathrm{ml}$ of blood was enumerated in a similar manner to that described above. Bacterial numbers were estimated as c.f.u. and expressed as $\log _{10}$ c.f.u.

Susceptibility of mice to LPS. To determine the susceptibility of mice to the lethal effect of LPS, mice were injected i.p. with graded doses of LPS from $P$. aeruginosa (strain P1-111). The LPS used after extraction by the phenol/water method (Westphal et al., 1952) was kindly donated by Dr Homma, Kitasato University, Tokyo. Deaths were recorded up to $5 \mathrm{~d}$ after challenge with LPS. Tolerance of mice to the lethal effect of LPS was established by consecutive injections with LPS in doses of $0.5 \mu \mathrm{g}, 1.0 \mu \mathrm{g}$ and $2.0 \mu \mathrm{g}$ every other day. Mice were challenged with LPS or $P$. aeruginosa $24 \mathrm{~h}$ after the last injection with LPS.

Assay of endotoxin in the blood. Blood from the femoral veins of mice was collected in tubes containing heparin. Plasma was obtained from the blood by centrifugation for $10 \mathrm{~min}$ at 2000 r.p.m. $(450 \mathrm{~g})$. To inactivate inhibitors, the plasma was boiled for $60 \mathrm{~min}$ after diluting twofold with endotoxin-free water. After boiling, the supernate was serially diluted 10 -fold with endotoxin-free water up to $10^{-6}$, and each dilution was transferred to test tubes containing Limulus polyphemus amoebocyte lysate (Wako Chemical Industries, Osaka, Japan) and incubated for $60 \mathrm{~min}$ at $37^{\circ} \mathrm{C}$. A tube showing the formation of a solid gel was taken as positive. In this procedure, gel formation occurred with $0 \cdot 1 \mathrm{ng}$ endotoxin (LPS). The original amount of endotoxin $\left(\mathrm{ng} \mathrm{ml}^{-1}\right)$ was calculated by the following formula: $0 \cdot 1 \mathrm{ng} \times 2 \times$ highest dilution showing positive reaction $=\mathrm{ng}$ endotoxin $\mathrm{ml}^{-1}$.

\section{RESULTS}

\section{Effect of $B C G$ pretreatment of mice on the mortality after challenge with $P$. aeruginosa}

Groups of mice treated with BCG or untreated were challenged i.v. with various doses of $P$. aeruginosa. The $\mathrm{LD}_{50}$ of $P$. aeruginosa by the i.v. route in normal mice was $3 \times 10^{6}$ c.f.u. Some of untreated control mice died on day 4 or 5 after challenge with $3 \times 10^{6}$ c.f.u. of bacteria. Mice treated with BCG before challenge showed a very high mortality irrespective of the time between $\mathrm{BCG}$ treatment and challenge (Table 1). In mice treated with $\mathrm{BCG}, 100 \%$ mortality was recorded after challenge with $1.8 \times 10^{6}$ c.f.u., while $80 \%$ of untreated mice survived this challenge dose. Moreover, death of mice treated with BCG was observed within $1 \mathrm{~d}$ after challenge in most cases. It is evident from these results that BCG enhances the susceptibility of mice to challenge with $P$. aeruginosa. Such an enhanced susceptibility was also observed when the challenge was by the i.p. or i.m. route. 
Table 1. Effect of BCG pretreatment of mice on the mortality after challenge with $P$. aeruginosa These results are typical of three experiments.

$\begin{array}{lcccc} & \begin{array}{c}\text { Interval between BCG } \\ \text { and challenge (d) }\end{array} & \begin{array}{c}10^{-6} \times \text { Challenge } \\ \text { dose (c.f.u.) }\end{array} & \begin{array}{c}\text { Mean survival time } \\ \text { of mice before } \\ \text { death (d) }\end{array} \\ \text { Untreated mice } & - & 1.8 & 2 / 10 & 4.0 \\ \text { Mice treated with BCG† } & - & 3.0 & 4 / 10 & 4.5 \\ & 7 & 3.0 & 10 / 10 & 1.8 \\ & 14 & 1.8 & 10 / 10 & 1.0 \\ & 14 & 3.0 & 9 / 9 & 1.0 \\ & 21 & 3.0 & 10 / 10 & 1.0\end{array}$

* Mortality is expressed as (no. dead)/(no. survived).

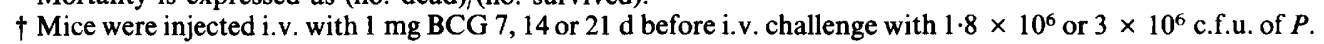
aeruginosa.

Table 2. Susceptibility of mice treated with BCG to challenge with P. aeruginosa, S. aureus and L. monocytogenes

\begin{tabular}{llcc} 
& \multicolumn{1}{c}{$\begin{array}{c}\text { Challenge } \\
\text { organism }\end{array}$} & Mortality* & $\begin{array}{c}\text { Mean survival time } \\
\text { of mice before } \\
\text { death }(\mathrm{d})\end{array}$ \\
Untreated mice & P. aeruginosa $\left(3.7 \times 10^{6}\right)$ & $6 / 10$ & 2.3 \\
BCG-treated mice† & P. aeruginosa $\left(3.7 \times 10^{6}\right)$ & $10 / 10$ & $1 \cdot 0$ \\
Untreated mice & S. aureus $\left(2.4 \times 10^{7}\right)$ & $7 / 8$ & 3.4 \\
BCG-treated mice† & S. aureus $\left(2.4 \times 10^{7}\right)$ & $6 / 8$ & $2 \cdot 0$ \\
Untreated mice & L. monocytogenes $\left(2.0 \times 10^{4}\right)$ & $6 / 10$ & 4.6 \\
BCG-treated mice† & L. monocytogenes $\left(2.0 \times 10^{4}\right)$ & $2 / 10$ & 6.0
\end{tabular}

* Mortality is expressed as (no. dead)/(no. survived).

† Mice were injected i.v. with $1 \mathrm{mg} \mathrm{BCG} 12 \mathrm{~d}$ before i.v. challenge.

Effect of BCG pretreatment on the susceptibility to challenge with $P$. aeruginosa in athymic nude mice and euthymic littermates

To determine whether cell-mediated immunity against BCG contributed to the enhanced susceptibility to pseudomonas challenge, athymic nude mice of BALB/C background were used. Athymic nude mice and heterozygous euthymic littermates were treated with BCG, and challenged with 1 or $5 \times 10^{6} P$. aeruginosa 2 weeks after BCG treatment. It was observed that all of the mice treated with BCG died within $1 \mathrm{~d}$ after challenge with $P$. aeruginosa. There was no difference in the pattern of death between $\mathrm{nu} /+$ and $\mathrm{nu} / \mathrm{nu}$ mice. It was apparent that cellmediated immunity against BCG did not contribute to the enhancement of susceptibility to $P$. aeruginosa.

Effect of BCG treatment on the susceptibility to infection with Gram-positive bacteria

To observe the effect of BCG treatment on the resistance or susceptibility to Gram-positive bacteria, $S$. aureus and $L$. monocytogenes, were used for challenge. There was no significant difference in the mortality between untreated mice and mice treated with BCG 2 weeks before the challenge with $S$. aureus (Table 2).

When the challenge was done with $L$. monocytogenes, the mortality was reduced in mice treated with BCG.

\section{Enumeration of $P$. aeruginosa in untreated mice or mice treated with $B C G$}

There was a possibility that the BCG-induced susceptibility to challenge with $P$. aeruginosa was due to enhanced bacterial growth in BCG-treated mice. To clarify this, the number of bacteria in thigh muscle inoculated with $1.5 \times 10^{5} P$. aeruginosa was counted 5, 24 and $48 \mathrm{~h}$ after the challenge. In both groups of BCG-treated or untreated mice, the number of organisms decreased continuously for $48 \mathrm{~h}$ (Fig. 1). With this challenge dose and route, no death was 


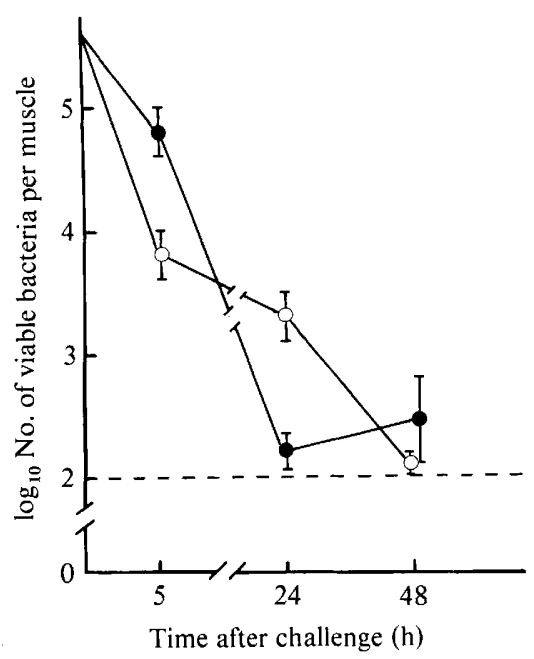

Fig. 1. Pattern of bacterial elimination in BCG-treated mice (O) or untreated mice $(O)$ after i.m. challenge with $1.5 \times 10^{5} P$. aeruginosa. Each point and bar indicates the mean results for five animals \pm S.D. Treatment with BCG was carried out 2 weeks before the challenge. The dashed line indicates the limit of detection for this system.

observed in either group of mice. As a follow up to this experiment bacterial counts in organs were compared from untreated and BCG-treated mice after an i.v. challenge with $1 \times 10^{6}$ bacteria several hours after challenge. Most of the BCG-treated mice became ill $10 \mathrm{~h}$ after challenge, and they were sacrificed along with control mice. The counts of bacteria in the spleen, liver, kidney and blood were enumerated. Data from two typical experiments revealed that the growth of bacteria in BCG-treated mice was similar to that in control mice. Thus BCG-induced susceptibility could not be attributed to enhanced growth of the challenge bacteria.

Next, bactericidal activity of macrophages and PMN was examined in vitro according to the method described by Van Furth \& Van Zwet (1973). Results from three experiments showed that $80 \%$ of the bacteria phagocytosed by phagocytes from BCG-treated or untreated mice were killed during $60 \mathrm{~min}$ in vitro incubation. No significant difference was found in the killing activities of macrophages or PMN between BCG-treated and untreated mice.

\section{Challenge of mice with killed bacteria}

Killed bacteria were used in the challenge dose to check whether viability is required for $P$. aeruginosa to express its lethal effect in BCG-treated mice. Bacteria were killed by heating half of the bacterial suspension at $70^{\circ} \mathrm{C}$ for $30 \mathrm{~min}$. The remaining suspension was used for the viable challenge and contained $4.7 \times 10^{6}$ c.f.u. $\mathrm{ml}^{-1}$. Mice treated with BCG 2 weeks previously were challenged i.v. with $4.7 \times 10^{6}$ viable or killed organisms. In the untreated group of mice, this dose of viable bacteria caused $60 \%$ deaths and the mean survival time was $4.5 \mathrm{~d}$; inoculation of $4.7 \times 10^{6}$ heat-killed bacteria did not cause death in untreated mice. If mice were treated with BCG 2 weeks before challenge, all mice died and there was a shortened survival time after challenge with killed bacteria. It was apparent that the enhanced mortality in BCGtreated mice was not due to enhanced bacterial growth or the lethal effect of $P$. aeruginosa exotoxin but to potentiation of a factor associated with killed organisms.

\section{Assay of endotoxin in plasma of mice after challenge with $P$. aeruginosa}

Pseudomonas aeruginosa possesses endotoxin in the cell wall and the possibility existed that the enhanced mortality might be attributable to the lethal effect of this endotoxin. To test this, the level of endotoxin in plasma was studied using the Limulus test. Plasma was obtained $6 \mathrm{~h}$ after challenge with $3 \times 10^{6} P$. aeruginosa from BCG-treated or untreated mice. In each case positive Limulus tests were observed in plasma diluted 1 in 2000; there was no evidence for greater quantities of endotoxin in BCG-treated mice. 


\section{Susceptibility of BCG-treated mice to lethal effect of LPS}

It has been reported that BCG-treated mice showed an enhanced susceptibility to the lethal effect of LPS (Howard et al., 1959; Suter et al., 1958). BCG-induced susceptibility to $P$. aeruginosa might be attributed to enhanced susceptibility of mice to bacterial LPS. Various doses of LPS from $P$. aeruginosa were injected i.p. into BCG-treated or untreated mice, and the mortality was measured. LPS in doses up to $100 \mu \mathrm{g}$ was not lethal to untreated mice. However, mice treated with BCG showed a striking increase in susceptibility to LPS. Even with $10 \mu \mathrm{g}$ LPS, all BCG-treated mice died within $1 \mathrm{~d}$; similar results were obtained in three experiments.

\section{Effect of tolerance induction against LPS on BCG-induced susceptibility to LPS}

Tolerance of mice against pseudomonas LPS (LPS tolerance) was established by repeated injections of very small doses of LPS into mice. A dose of $10 \mu \mathrm{g}$ LPS was lethal for BCG-treated mice, all mice (10/10) dying within $1 \mathrm{~d}$. On the other hand no deaths occurred in BCG-treated mice that received the same dose of LPS after being made tolerant to LPS: indeed 8/10 tolerant mice even survived the injection of $25 \mu \mathrm{g}$ LPS. In LPS-tolerant BCG-treated mice $7 / 10$ animals survived the challenge with $3 \times 10^{6}$ viable $P$. aeruginosa. Similar results were obtained in repeat experiments.

\section{DISCUSSION}

Mice treated with BCG showed an enhanced susceptibility to $P$. aeruginosa. This BCGinduced susceptibility, which was characterized by an increased mortality and a shortened survival time, was observed as early as 1 week after BCG treatment. The results obtained in this study demonstrated that BCG-induced susceptibility to $P$. aeruginosa was not due to any impairment of the ability to eliminate bacteria, but was probably due to an enhanced susceptibility to bacterial endotoxin.

LPS produces a variety of biological effects in experimental animals, including hypothermia, leucopenia and death. In mice challenged with $P$. aeruginosa, it is to be expected that the bacteria will be phagocytosed and digested. In the course of degradation of bacterial cells it is likely that LPS will be released into the circulation. In our study there were no changes in the kinetics of bacterial elimination or in bactericidal activity of phagocytes in BCG-treated mice as compared with those in untreated mice. Therefore, enhanced or rapid release of a greater amount of LPS in BCG-treated mice can be excluded. Results with the Limulus test indicated that the amount of LPS in the circulation was not affected by BCG treatment.

It seems likely then that enhanced susceptibility of BCG-treated mice to $P$. aeruginosa resembles BCG-induced hyperreactivity to LPS reported by Suter et al. (1958). BCG-induced hyperreactivity was expressed only against the lethal effect of LPS and not against the pyrogenic effect or skin-necrotizing effect (Suter, 1964). In spite of extensive studies on this phenomenon, the precise mechanism for it has not been elucidated. In recent years, prostaglandin has been regarded as an important mediator of endotoxin action (Rietschel et al., 1980), but it is not clear whether the lethal effect of LPS is mediated only by this substance. Macrophages are reported to synthesize and release prostaglandins after stimulation with LPS. BCG-induced peritoneal macrophages are also reported to release a large amount of prostaglandins, so that one possibility is that BCG-induced hyperreactivity to a lethal effect is due to some synergistic effect of BCG and LPS on the release of prostaglandins by macrophages. An alternative possibility may be the destruction of macrophages and release of some vasoactive substances from them. This possibility is supported by a report showing that LPS caused a dose-dependent decrease in the survival of macrophages from BCG-treated mice (Peavy et al., 1979). In any case, the precise mechanism of BCG-induced hyperreactivity to LPS should be clarified in the future.

In conclusion, our findings on BCG-induced enhancement of death against pseudomonas infection should be taken into consideration in relation to the use of BCG as an immunomodulator.

The technical assistance of Dr Sachio Sumita (Fukuoka Central Hospital) in the Limulus test is gratefully acknowledged. 


\section{REFERENCES}

Benett, J. V. (1974). Nosocomial infections due to pseudomonas. Journal of Infectious Diseases 130 (supplement), S4-S7.

BuHles, W. C. \& Shiferine, M. (1977). Adjuvant protection against bacterial infection in granulocytopenic mice. Journal of Infectious Diseases 136, 90-95.

Chedid, L. \& PaRant, M. (1971). Role of hypersensitivity and tolerance in reactions to endotoxins. In Microbial Toxins, vol. 5, pp. 415-459. Edited by W. Weinbaum, S. Kadis \& S. I. Aji. New York: Academic Press.

Howard, J. G., Biozzi, G., Halpern, B. N., Stiffel, C. \& MouToN, D. (1959). The effect of Mycobacterium tuberculosis (BCG) infection on the resistance of mice to bacterial endotoxin and Salmonella enteritidis infection. British Journal of Experimental Pathology 40, 281-290.

LiEbERMANN, M. M., WRight, G. L., WolcotT, K. M \& MCKissock-Desoto, D. C. (1980). Polyvalent antisera to pseudomonas ribosomal vaccines: protection of mice against clinically isolated strains. Infection and Immunity 29, 489-493.

Matsuo, K., Nomoto, K., Shimotori, S. \& TAKeYA, K. (1977). Depression of protective mechanism against microorganism in tumor-bearing mice and its restoration by adjuvants. Gann 68, 465-471.

Matsumoto, K., Ogawa, H., Kusama, T., Nagase, O., Sawaki, S., InaGe, M., Kusomoto, S., Shiba, T. \& Azuma, I. (1981). Stimulation of non specific resistance to infection induced by 6-O-acyl muramyl dipeptide analogs in mice. Infection and Immunity 32, 748-758.

Miyata, H., Nomoto, K. \& TakeyA, K. (1980). Characteristics of resistance against Listeria monocytogenes enhanced by Corynebacterium parvum in mice. Immunology 40, 33-39.

Peavy, D. L., Baughn, R. E. \& Muscher, D. M. (1979). Effects of BCG infection on the susceptibility of mouse macrophage to endotoxin. Infection and Immunity 24, 59-64.

Pier, G. B., Sideberry, H. F. \& SAdoff, J. C. (1978). Protective immunity induced in mice by immunization with high-molecular-weight polysaccharide from Pseudomonas aeruginosa. Infection and Immunity 22, 919-925.

Reinarz, J. A., Megna, M. J. \& Brown, G. T. (1979). Nosocomial infection: time for accountability. In Infectious Diseases, Current Topics, vol. 1, pp. 219240. Edited by D. N. Gilbert \& J. P. Sandford. New York: Grune \& Stratton.

ReYNolds, H. Y., LeVINE, A. S., WoOd, R. E., ZIERDT, C. H., Dale, D. C. \& Pennington, J. E. (1975). Pseudomonas aeruginosa infections: Persisting problems and current research to find new therapies. Annals of Internal Medicine 82, 819-831.

RIETSCHEL, E. T., SCHADE, V., LÜDERITZ, O., Fischer, H. \& Peskar, B. A. (1980). Prostaglandin in endotoxocosis. In Microbiology, pp. 66-72. Washington, D.C.: American Society for Microbiology.

SUTER, E. (1964). Hyperreactivity to endotoxin after infection with BCG. Studies on its distinguishing properties. Journal of Immunology 92, 49-54.

Suter, E., Ullman, G. E. \& Hofrman, R. G. (1958). Sensitivity of mice after vaccination with BCG (Bacillus Calmette-Guérin 24282). Proceedings of the Society for Experimental Biology and Medicine 99, 167-169.

Takeya, K., Nomoto, K., Muraoka, S., Shimotori, S., TANiguchI, T. \& MrYaKe, T. (1977). Growth of two strains of Mycobacterium bovis (BCG) in athymic mice. Journal of General Microbiology 100, 403-405.

Tatsukawa, K., Mitsuyama, M., Takeya, K. \& Noмото, K. (1979). Differing contribution of polymorphonuclear cells and macrophages to the protection against Listeria monocytogenes and Pseudomonas aeruginosa. Journal of General Microbiology 115, 161-166.

VAN FURTH, R. \& VAN ZWET, T. L. (1973). In vitro determination of phagocytosis and intracellular killing by polymorphonuclear and mononuclear phagocytes. In Handbook of Experimental Immunology, 2nd edn, ch. 24. Edited by D. M. Weir. Oxford: Blackwell Scientific Publications.

WestPhal, O., LÜderitz, O. \& BisteR, F. (1952). Extraction of bacteria with phenol/water. Zeitschrift für Naturforschung 7b, 148-155. 